\title{
Intra-individual variability and adaptation of overnight- and sleeping metabolic rate
}

Citation for published version (APA):

Schoffelen, P. F. M., \& Westerterp, K. R. (2008). Intra-individual variability and adaptation of overnightand sleeping metabolic rate. Physiology \& Behavior, 94(2), 158-63.

https://doi.org/10.1016/j.physbeh.2007.12.013

Document status and date:

Published: 01/01/2008

DOI:

10.1016/j.physbeh.2007.12.013

Document Version:

Publisher's PDF, also known as Version of record

Document license:

Taverne

Please check the document version of this publication:

- A submitted manuscript is the version of the article upon submission and before peer-review. There can be important differences between the submitted version and the official published version of record.

People interested in the research are advised to contact the author for the final version of the publication, or visit the DOI to the publisher's website.

- The final author version and the galley proof are versions of the publication after peer review.

- The final published version features the final layout of the paper including the volume, issue and page numbers.

Link to publication

\footnotetext{
General rights rights.

- You may freely distribute the URL identifying the publication in the public portal. please follow below link for the End User Agreement:

www.umlib.nl/taverne-license

Take down policy

If you believe that this document breaches copyright please contact us at:

repository@maastrichtuniversity.nl

providing details and we will investigate your claim.
}

Copyright and moral rights for the publications made accessible in the public portal are retained by the authors and/or other copyright owners and it is a condition of accessing publications that users recognise and abide by the legal requirements associated with these

- Users may download and print one copy of any publication from the public portal for the purpose of private study or research.

- You may not further distribute the material or use it for any profit-making activity or commercial gain

If the publication is distributed under the terms of Article $25 \mathrm{fa}$ of the Dutch Copyright Act, indicated by the "Taverne" license above, 


\title{
Intra-individual variability and adaptation of overnight- and sleeping metabolic rate
}

\author{
Paul F.M. Schoffelen *, Klaas R. Westerterp \\ Department of Human Biology, Maastricht University, Maastricht, The Netherlands
}

Received 6 September 2007; received in revised form 21 November 2007; accepted 18 December 2007

\begin{abstract}
The largest component of daily energy expenditure is resting energy expenditure as reflected in overnight metabolic rate (OMR) and sleeping metabolic rate (SMR). Here, we determined the variation in OMR (24:00-6:00 h) and SMR values (3 h intervals) as affected by physical activity (PA) during the day and the night. Subjects were 32 females and 17 males, age 18-52 years. Energy expenditure (EE) was measured for $36 \mathrm{~h}$ in a whole room calorimeter $\left(14 \mathrm{~m}^{3}\right)$, starting in the evening, providing values before and after behavioral limitation. The mean intra-individual coefficient of variation was $1.8 \pm 1.4 \%$ for $\mathrm{SMR}_{\min }$ (minimum EE), $2.8 \pm 2.0 \%$ for $\mathrm{SMR}_{\text {act }}$ (minimum PA), $2.4 \pm 2.5 \%$ for $\mathrm{SMR}$ res $($ minimum residual EE, residual calculated from $24 \mathrm{~h}$ relationship between EE and PA) and $2.8 \pm 2.2 \%$ for OMR $(n=49)$. Mean clock time for SMR ranged from 3:15 till 4:13 h. EE and PA increased in the hour before awakening. Surprisingly, OMR showed a significant $2.7 \%$ increase $(P<0.05)$ during the second night of the $36 \mathrm{~h}$ measurement, but only for a second visit, and was related to increased physical activity during night period $\left(R^{2}=0.50\right.$, $P<0.001$ ). OMR measurements following unrestricted daily activity showed identical results for first and second (repeat) visits: $6.82 \pm 0.86 \mathrm{MJ} /$ day and $6.79 \pm 0.93 \mathrm{MJ} /$ day $(n=49)$, respectively. It is advised to measure SMR based on minimum residual EE during nights following free-living conditions, and to exclude EE measures $1 \mathrm{~h}$ before awakening from SMR and OMR calculations to prevent influences of habitual wake-up time. (C) 2008 Elsevier Inc. All rights reserved.
\end{abstract}

Keywords: Sleeping metabolic rate; Overnight metabolic rate; Whole room calorimetry; Respiration chamber; Activity measurement; Residual energy expenditure; Intra-individual variation; Habitual wake-up time

\section{Introduction}

The largest component of 24-h energy expenditure (24hEE) is resting energy expenditure as reflected in overnight metabolic rate (OMR) and its derivative sleeping metabolic rate (SMR). The other two components of $24 \mathrm{hEE}$ are activity-induced energy expenditure (AEE) and diet-induced energy expenditure (DEE) [1-5]. In this study OMR and SMR using three different methods were measured. Based on variability, and by reviewing modulating factors, an advice is formulated for measuring this major component of daily energy expenditure.

\footnotetext{
* Corresponding author. Department of Human Biology, Maastricht University, PO Box 616, 6200 MD Maastricht, The Netherlands. Tel.: +31 43 3881642; fax: +31433670976 .

E-mail address: P.Schoffelen@HB.Unimaas.NL (P.F.M. Schoffelen).
}

The measurement of OMR and SMR is usually performed inside a whole room calorimeter [3,5-20], effectively limiting the subjects' activity due to the confined space. Westerterp and Kester [3] showed a decrease in physical activity level (PAL = 24hEE/SMR) from 1.76 to 1.40 for subjects when confined to a $14 \mathrm{~m}^{3}$ whole room calorimeter. Garby et al. [13] found no effect of an activity program (PAL range 1.30 to 1.53 ) on SMR once inside a whole room calorimeter, neither did Goldberg et al. [5]. The reported variability in SMR of about $2 \%$ as observed in whole room calorimeter measurements is generally ascribed to this lower level of AEE $[8,9,11,15]$. However, in contrast to other SMR studies [21-24] a whole room calorimeter will allow normal sleep without facemask, hood or probes [5,17] and is generally considered the instrument of choice for studying night time metabolism.

Several other factors have been shown to modulate overnight metabolic rate and sleeping metabolic rate, including sleep stages, menstrual and seasonal cycles, temperature, diet-induced energy 
expenditure, daily physical activity and body movement during the night $[12-16,18-20]$. Unexpected, sleep stages play only a minor role in SMR variability $[3,9,12]$. In women, SMR shows an increase in the range of $8 \%$ to $16 \%$ during the post ovulation phase of the menstrual cycle $[14,23,25]$. Season affects SMR with $4.5 \%$ difference when comparing the summer-low with the winter-high [10]. When subjects stayed in a whole room calorimeter for $60 \mathrm{~h}$ at a temperature of $16^{\circ} \mathrm{C}$ in comparison to $22^{\circ} \mathrm{C}$, SMR increased 5.6\% [26]. The effect of DEE was demonstrated by overfeeding in a late night meal, causing a $6.7 \%$ increase in OMR [5]. Twelve weeks of energy restriction to 2.9-3.5 MJ/day in obese women caused a decline in SMR of 29.9\% [27]. Here we focus on short-term variability of overnight metabolic rate and sleeping metabolic rate.

A steady decrease pattern for SMR, with a low just before wakening of subjects, has been reported [20]. Others found that SMR was at its lowest between 4:00 and 6:00 $\mathrm{h}[6,12,28]$. The latter corresponds with the moment of the lowest residual EE [18], calculated as the residual of the individual relationship between energy expenditure and physical activity (PA) over $24 \mathrm{~h} \mathrm{[4]}$, and the time of lowest heat production [13]. A decline in OMR, only for subjects that were fed a late night meal, while other subjects were found to have a relatively constant and lower overnight metabolic rate, was also reported [5]. The measurement of OMR and SMR will thus be dependent on the interval chosen.

The activity component during the night has either been measured [9,20,26,27], discarded [16] or ignored by way of selecting minimum measured energy expenditure [5,19]. Systems for measurement of body movement were accelerometry [19], force-platform [20], level-detection $[1,16]$ and analog doppler $[9,17]$. In contrast with the latter analog system, both forceplatform and level-detection require a minimum activity $[1,16]$, thus exhibiting a "decrease to nearly zero" [20] during the lowest activity period in the night. An advice with regard to the method of choice for incorporating activity measurements as well as regarding the impact of activity during the day has not yet been postulated.

The consistent message in the aforementioned publications was that the significant causes for variation in SMR measurements, if conducted in a whole room calorimeter with a thermoneutral setting, are body movement during the night and dietinduced energy expenditure. Yet, in contrast to the impact of diet-induced energy expenditure the impact of physical activity, both during the day and the night, has been relatively ignored. Here, two mechanisms can be postulated, the impact of the transition from free-living conditions to the confined space of a whole room calorimeter and the impact of activity during the night. Additionally, studies have been hampered by the lack of definition of time-interval. Fixed interval measurements like OMR are generally well-defined, with the exception of intervals being excluded due to subject activity [16]. In contrast SMR measures over a variable interval, for instance the lowest continuous $60 \mathrm{~min}$ EE value [5,19], the continuous average over $3 \mathrm{~h}$ with most stable EE value [19] and the continuous average over $3 \mathrm{~h}$ with lowest activity measure $[10,27]$, have in general not provided defined intervals.
In this study a subject group typical for whole room calorimeter studies was observed, originating from $36 \mathrm{~h}$ experiments where intervention between visits was limited to dietary effects on ad-lib energy requirements. Potential confounders as described above were kept to a minimum and all experiments used the same protocol. The analysis can thus be considered a best choices meta-analysis.

The application context here was concerned with diminishing the role of activity and time as confounders for OMR and SMR, resulting in advice for choosing the most reproducible method and moment in time as well as for incorporating activity measurements into a less confounded SMR measure. The study thus aimed to answer two questions. Firstly, how does SMR progress during the night in relation to body movement and the residual energy expenditure with attention to time-interval? Secondly, is there an impact on OMR and SMR stemming from the transition from free-living conditions to the behavioral limitation inside the confined space of a whole room calorimeter?

\section{Methods}

Data on whole room calorimeter experiments originated from unpublished and published studies from the Maastricht respiration chambers over the period 2004-2007. The selection included low impact diet intervention experiments with healthy adult subjects, measured over $36 \mathrm{~h}$ intervals and starting at 19:00 h. Furthermore subjects were measured on a first and second visit $(n=49$, Table 1), where the first visit was the subject's first experience in a whole room calorimeter. Inter-visit interval was $32 \pm 18$ days, range 5-91 days. Female subjects were studied in the same phase of the menstrual cycle on both visits. The $36 \mathrm{~h}$ protocol provided for a designated sleeping period from 23:00 h till 7:30 h, furthermore subjects were asked to refrain from unusual or heavy exercise on the day preceding measurements. Subjects provided written informed consent and were assessed by medical history. The Medical Ethical Committee of Maastricht University approved experiments.

Whole room calorimeter measures were taken in a dual respiration chamber system with automated calibration [17]. The analysis system consisted of dual pairs of infra-red $\mathrm{CO}_{2}(\mathrm{ABB} /$ Hartman\&Braun Uras, Frankfurt a.M., Germany) and paramagnetic $\mathrm{O}_{2}$ analysers (Servomex 4100, Crowborough, England and ABB/Hartman\&Braun Magnos, Frankfurt a.M., Germany). Flow was measured using electronically modified dry gasmeters (G6, gasmeterfabriek Schlumberger, Dordrecht, The Netherlands). Data-acquisition was performed using custom build interfaces (IDEE, University of Maastricht, the Netherlands), a computer (Apple Macintosh, Cupertino, United states) and graphical programming environment (Labview, National Instruments, Austin, United states). Each room had a volume of $14 \mathrm{~m}^{3}$

Table 1

Subject characteristics (mean $\pm \mathrm{SD})$

\begin{tabular}{lllll}
\hline & Age (years) & Height $(\mathrm{m})$ & Weight $(\mathrm{kg})$ & Body fat $(\%)$ \\
\hline Women $(n=32)$ & $23 \pm 6$ & $1.70 \pm 0.06$ & $66.5 \pm 8.8$ & $27.7 \pm 6.8$ \\
Men $(n=17)$ & $26 \pm 8$ & $1.81 \pm 0.11$ & $75.0 \pm 9.7$ & $14.4 \pm 6.5$ \\
\hline
\end{tabular}


with $6.4 \mathrm{~m}^{2}$ floorspace and was furnished with a bed, chair, radio and television, computer, laptop network connection, telephone, hands-free intercom, deepfreeze toilet, hot and cold running water and a desk with built in sink. The rooms had a controlled climate and could be operated from 16 to $28{ }^{\circ} \mathrm{C}$. Subjects were allowed to select their own thermal comfort zone, resulting in a setting $0-3^{\circ}$ higher then at home, in order to compensate for the effects of draught inside the room. The temperature measured was $21.9 \pm 0.9^{\circ} \mathrm{C}$, range $19.8-25.3^{\circ} \mathrm{C}, n=49$. Humidity was $51 \pm 5 \%$, range $11-18 \mathrm{mBar} \mathrm{H}_{2} \mathrm{O}$. Ambient pressure was $1009 \pm 8 \mathrm{mBar}$, range $979-1025 \mathrm{mBar}$. Recirculation flow inside the room was at its lowest setting of $1100 \mathrm{l} / \mathrm{min}$ and flow through the rooms was set at $100 \mathrm{l} / \mathrm{min}$ STPD. Safety measures included fire alert and on-line gas analysis with cellular phone alert. The calorimeter was validated on a monthly interval with methanol burning. Oxygen and carbon dioxide measures were converted to energy expenditure in Joules using the Weir formula [29], values are presented in $\mathrm{MJ} / \mathrm{day}$ by extrapolating the measured energy expenditure to $24 \mathrm{~h}$. Physical activity was measured with an analog ultrasound doppler system, directly processing the analog Doppler signal from inside the sensor (Advisor DU160, Aritech BV, Roermond, Netherlands).

OMR was calculated over the 24:00 till 6:00 $\mathrm{h}$ interval. For SMR measurements, data from the 23:00 till 7:00 $\mathrm{h}$ interval was evaluated, providing compatibility with broader intervals found in literature $[2,5,15]$ and providing for SMR results to be found outside the here defined OMR interval if present. SMR measures were calculated for continuous intervals. $\mathrm{SMR}_{\min }$ was defined as the lowest EE value over a $3 \mathrm{~h}$ interval. SMR res was defined as the $\mathrm{EE}$ value over a $3 \mathrm{~h}$ interval with the lowest residual energy expenditure $\left(\mathrm{EE}_{\mathrm{res}}\right)$, calculated as the residual of the individual relationship between energy expenditure and physical activity over $24 \mathrm{~h} \mathrm{[4]} \mathrm{as} \mathrm{a} \mathrm{measure} \mathrm{of} \mathrm{diet-induced} \mathrm{energy} \mathrm{expenditure}$ and diurnal variation of energy expenditure required for maintaining body temperature: For each experiment linear regression of activity $(\operatorname{ACT}(t))$ and energy expenditure $(\operatorname{EE}(t))$ over exactly $24 \mathrm{~h}$, calculated from 48 individual $30 \mathrm{~min}$ values, yielded slope $(a)$ and intercept $(b)$ values. The residual energy values were then calculated as $\mathrm{EE}_{\text {res }}(t)=\mathrm{EE}(t)-a \cdot \operatorname{ACT}(t)-b$. For this method an analog movement detection system, with continuous values from zero movement upward, was deemed a requirement. $\mathrm{SMR}_{\text {act }}$ was defined as the EE value over a $3 \mathrm{~h}$ interval with lowest physical activity as measured by the ultrasound system.

OMR and SMR values for the subsequent nights, one after normal daily behavior in free-living conditions (night 1) and one after spending a night and day inside the whole room calorimeter (night 2), were calculated for each visit.

The intra-individual variability was assessed for subsequent nights, providing a short-term measurement of variability without influence of seasonal [10] and hormone cycle $[14,23,25]$ variation. Subjects were measured in their thermoneutral comfort zone and were not provided with food after dinner, i.e. after 20:00 h, eliminating the impact of ambient temperature variation $[26,9]$ and restricting the impact of diet-induced energy expenditure as described before [5] as well as decreasing the impact of body temperature variation $[13,21]$.
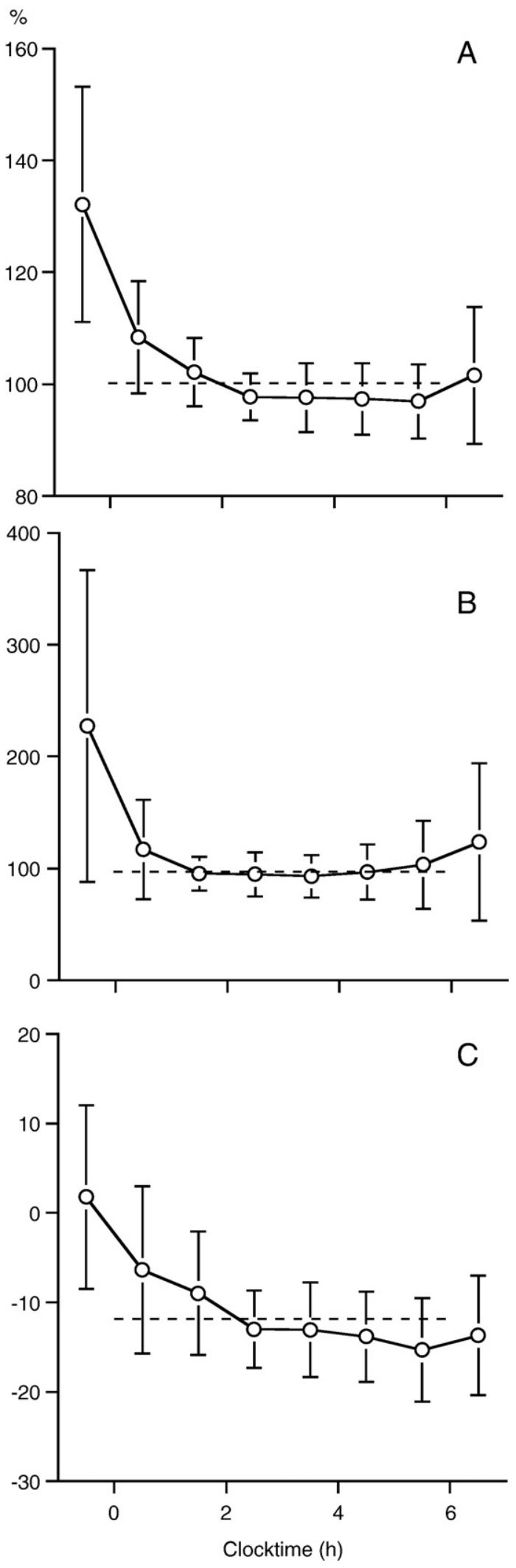

Fig. 1. Energy expenditure (A), physical activity (B), and residual energy expenditure (C). Hourly values from 23:00 to 7:00 h expressed as percentage of the mean value of the overnight values from 24:00 to 6:00 $\mathrm{h}$ (dotted line). 
Table 2

Overnight metabolic rate (OMR, 0:00-6:00 h) measures, sleeping metabolic rate (SMR) measures with mean time value, respiratory quotient (RQ) and estimated basal metabolic rate $\left(\mathrm{BMR}_{\mathrm{est}}\right)$ for the same subjects on two separate visits

\begin{tabular}{|c|c|c|c|c|c|c|c|}
\hline & Night 1 (MJ/day) & Mean time (hh:mm) & RQ & Night 2 (MJ/day) & Mean time (hh:mm) & RQ & $\mathrm{Cv}(\%)$ \\
\hline \multicolumn{8}{|l|}{ Visit 1} \\
\hline OMR & $6.82 \pm 0.86$ & 03:00 & 0.85 & $6.87 \pm 0.80$ & 03:00 & 0.85 & $2.8 \pm 2,2$ \\
\hline $\mathrm{SMR}_{\min }$ & $6.48 \pm 0.77$ & $04: 14$ & 0.86 & $6.49 \pm 0.75$ & $04: 28$ & 0.86 & $1.8 \pm 1.4$ \\
\hline $\mathrm{SMR}_{\text {res }}$ & $6.60 \pm 0.83$ & 04:07 & 0.87 & $6.60 \pm 0.87$ & $04: 16$ & 0.86 & $2.4 \pm 2.5$ \\
\hline \multicolumn{8}{|l|}{ Visit 2} \\
\hline $\mathrm{SMR}_{\mathrm{act}}$ & $6.60 \pm 0.84$ & $02: 54$ & 0.85 & $6.67 \pm 0.78$ & $03: 43^{* *}$ & 0.84 & $3.6 \pm 3.0$ \\
\hline $\mathrm{SMR}_{\text {res }}$ & $6.48 \pm 0.82$ & $04: 12$ & 0.86 & $6.57 \pm 0.77$ & 04:33 & 0.86 & $2.9 \pm 3.1$ \\
\hline $\mathrm{BMR}_{\text {est }}$ & $6.67 \pm 0.98$ & & & & & & \\
\hline
\end{tabular}

For OMR, calculated over the 0:00 $\mathrm{h}$ till 6:00 h period, the mean time equals 3:00 h. SMR values are presented for $3 \mathrm{~h}$ minimum energy expenditure $\left(\mathrm{SMR}_{\min }\right)$, minimum physical activity $\left(\mathrm{SMR}_{\mathrm{act}}\right)$ and minimum residual energy expenditure ( $\left.\mathrm{SMR}_{\mathrm{res}}\right)$. The intra-individual coefficient of variation and mean time of interval used in this article were from the first visits nights, as these were not significantly different for OMR, SMR and mean time values. A significant increase in OMR for the second night of the second visit was observed, as well as a significant shift in mean time for SMR $\mathrm{Sct}_{\text {. }}$ Cv of $\mathrm{SMR}_{\min }$ value for the second visit was significantly elevated in comparison to visit 1 .

$* P<0.05$.

$* * P<0.001$.

Basal metabolic rate $\left(\mathrm{BMR}_{\text {est }}\right)$ was estimated from subject characteristics height, weight, age and gender [30]. Body composition was determined by underwater weighing in the morning upon leaving the chamber.

Statistical analysis was performed using Statview software (Abacus concepts inc, Berkeley, United States), significance was based on two-sided paired $T$-tests and individual $\mathrm{Cv} \%$ values were calculated as $100 \times$ the unbiased standard deviation of the difference divided by the mean value. Furthermore $\mathrm{Cv} \%$ values were not corrected for measurement noise, responsible here for $0.4 \%$ of reported $\mathrm{Cv} \%$ [15].

\section{Results}

There were no significant or trend-like changes in ambient factors between visits and nights, temperatures were statistically identical.

Energy expenditure showed a rapid decline after 23:00 h, the time subjects prepared for the night, until 2:00 $\mathrm{h}$ followed by a steady decrease till the 5:00-6:00 $\mathrm{h}$ interval and a rise during the 6:00-7:00 $\mathrm{h}$ interval before wakening (Fig. 1A). Physical activity showed a similar decrease between 23:00 h and 2:00 h, followed by a plateau until approximately $5: 00 \mathrm{~h}$ and then a rise in activity before wakening (Fig. 1B). The residual of the individual relationship between energy expenditure and physical activity, as a measure for diet-induced energy expenditure and the variation in energy expenditure required for maintaining body temperature, showed a decrease over the night until a minimum was reached between 5:00 h and 6:00 h (Fig. 1C).

On the first visit, there was no significant difference between expenditure measures for night 1 and night 2 . The mean intraindividual variation for these nights was the smallest for $\mathrm{SMR}_{\min }$ and $\mathrm{SMR}_{\text {res }}$ with a value of $1.8 \pm 1.4$ and $2.4 \pm 2.5 \%$, respectively (Table 2). The mean clock time for measured $3 \mathrm{~h}$ intervals varied from $3: 15 \mathrm{~h}$ till $4: 13 \mathrm{~h}$, indicating that the $3 \mathrm{~h}$ minima for $\mathrm{EE}_{\min }, \mathrm{EE}_{\text {act }}$ and $\mathrm{EE}_{\text {res }}$ were on average all found within the 1:45 $\mathrm{h}$ till 5:43 $\mathrm{h}$ time frame.

Expenditure values of a second night showed a tendency to be higher, this difference was found to be larger at a second visit to the whole room calorimeter. On a first visit there was no significant difference between night 1 and night 2 , whereas on a second visit the OMR for the second night increased $2.7 \%$ $(P<0.05, n=49)$. The increase in OMR on the second night of a second visit was related to physical activity (Fig. 2). The mean intra-individual variation values for the second visit were deemed confounded in light of the simultaneous increase in OMR during these nights.

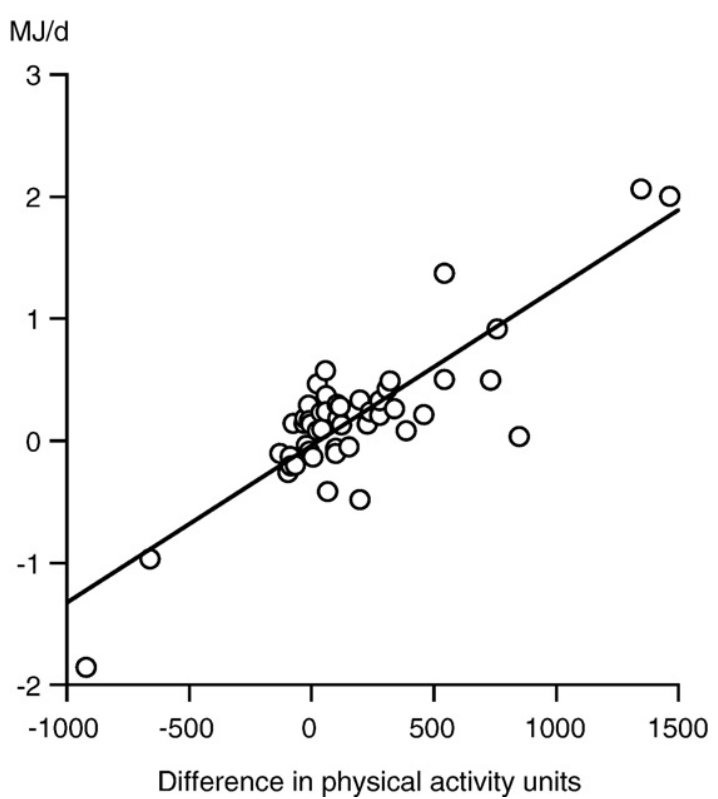

Fig. 2. Difference in energy expenditure between night 1 and night 2 (24:006:00 h) for a second visit to the respiration chamber, in relation to the difference in physical activity for the same interval. 
The clock time for $\mathrm{SMR}_{\mathrm{act}}$ showed a shift of $50 \mathrm{~min}(P<0.001)$ on the second visit, which was the only significant shift in clock times found.

There was no significant difference in SMR and OMR measures when comparing night 1 of the first and second visit. There was no significant difference in respiratory quotient (RQ) values between nights and visits, except for a small difference in RQ values between residual and activity methods $(P<0.01)$.

\section{Discussion and conclusions}

The shape of the energy expenditure curve during the night (Fig. 1A) was similar to earlier observations by Fontvieile et al. [12], Garby et al. [13] and others [6,28], with a minimum in the 4:00 $\mathrm{h}$ to $6: 00 \mathrm{~h}$ interval. Zhang et al. [20] also found a steady decline in energy expenditure during the night, but with the minimum just before wakening the subjects. The change in overnight energy expenditure curve can be seen to be the combination of physical activity (Fig. 1B) and residual energy expenditure (Fig. 1C), both of which show a rapid decline till approximately $2: 00 \mathrm{~h}$. The phase relation of the figures indicates that the combined decline is for the greater part initially driven by the decline in activity, while the decline of the residual is of a smaller percentage but progressing longer into the night. The $Y$-axis of Fig. 1 is expressed in relative percentages, and although activity (Fig. 1B) might seem to decline in advance of measured energy expenditure (Fig. 1A) this is not the case but merely illustrates this larger initial decline of activity. Garby et al. [13] and Webb [31] showed that subjects are not in heat balance during the night, where subjects heat-loss is different from subjects heat production, i.e. subjects are losing heat to the ambient resulting in a lowering of body temperature. During the interval from 2:00 till 6:00 $\mathrm{h}$ diet-induced energy expenditure together with subjects decline in body temperature is thought to be the main cause for the remaining slow decline in energy expenditure, while the effect of activity remained at an almost constant plateau value from 2:00 h till 5:00 h. After 5:00 h physical activity started to increase.

In contrast to the energy expenditure curve found here, Goldberg et al. [5] reported a relatively constant overnight metabolic rate, unless a late night meal was provided. The effect of diet-induced energy expenditure thus must have had a faster rate of decline than in our setting, possibly related to the size of the last meal. The absence of an increase in energy expenditure before awakening, as found in research by both Goldberg et al. [5] and Zhang et al. [20], was speculated on by Zhang et al. [20] as being caused by not allowing subjects to wake naturally, i.e. due to staff awakening the subjects. The data presented here agreed with this speculation and it is suggested that depending on subject group characteristics the effect of circadian pattern may cause subjects to wake naturally at a different time due to differences in habitual sleep time. Fraser et al. [22] concluded that the circadian cycle was a main factor controlling sleeping metabolic rate, and though Fraser et al.'s [22] conclusion that the rapid decrease of energy expenditure at the onset of sleep was not related to diet-induced energy expenditure did not agree with the data presented here, the subjects habitual circadian pattern may indeed have resulted in differences in activity and restoration of body temperature between subject groups as observed in the hours before awakening. The observed intraindividual variability for OMR of $2.8 \%$ (Table 2) was comparable to OMR variability found in literature $[5,8,15]$ of 1.4 to $2.7 \%$. The variability found here can be ascribed in part to the smaller OMR interval used, causing a decrease in variability due to the lesser impact of physical activity in the selected interval, and in part to the effect of natural awakening as observed in the subject group causing an increase in variability. During the night the intra-individual variability decreased to $1.8 \%$ for $\mathrm{SMR}_{\min }$ and $2.4 \%$ for $\mathrm{SMR}_{\text {res }}$ as effects of residual energy expenditure and activity decreased.

The different definitions of the time-interval chosen for OMR and SMR will yield different values. Wouters-Adriaens and Westerterp [19] defined SMR as the $3 \mathrm{~h}$ interval with most stable energy expenditure, which was $4.6 \%$ below BMR. Here, the $\mathrm{SMR}_{\text {min }}$ and $\mathrm{SMR}_{\text {res }}$ were $5.0 \%$ and $3.3 \%$ lower respectively in comparison to overnight metabolic rate $(P<0.001, P<0.0001)$. The results acquired from minimal residual energy expenditure in our view provide the best measure for selecting sleeping metabolic rate intervals when incorporating physical activity measurements, furthermore it is deemed advisable to restrict OMR and SMR measurement intervals to at least $1 \mathrm{~h}$ before wakening the subjects or alternatively to before $6: 00 \mathrm{~h}$.

One surprising aspect of this study was the fact that on the second night of the $36 \mathrm{~h}$ protocol, after the relative calm of confined behavior, the overnight metabolic rate increased significantly. An early indication of this effect was found when 160 experiments with a $36 \mathrm{~h}$ protocol as used in this study were evaluated, and an increase in OMR for the second night of $1.4 \%(P=0.01)$ was found. The smaller dataset presented here results in lower significance $(P<0.05)$ but also offers an explanation for the found effect; subjects' first experience in a whole room calorimeter is different from repeat experiments when subjects have already become accustomed to the laboratory setting. This is illustrated by the fact that on a first visit no significant differences between OMR and SMR values for the two nights in the $36 \mathrm{~h}$ experiments are found (Table 2), however, on the second visit a significantly elevated OMR as well as a trend towards an increase in SMR for the second night of the $36 \mathrm{~h}$ experiment was observed. Since there was no significant difference in OMR, SMR and temperature for night 1 of the first and second visit it seems unlikely that any form of intervention other then behavioral adaptation causes this increase in metabolism. For energy expenditure measurements following a $36 \mathrm{~h}$ protocol, and possibly longer protocols, it is advisable to use the night following free-living conditions for OMR and SMR evaluation.

\section{Acknowledgements}

Authors would like to thank M.P. Lejeune, A. Smeets and A. Hochstenbach-Waelen for the contribution of data from their experiments. 


\section{References}

[1] Jequier E, Schutz Y. Long-term measurements of energy expenditure in humans using a respiration chamber. Am J Clin Nutr 1983;38(6): 989-98.

[2] Rumpler WV, Seale JL, Conway JM, Moe PW. Repeatability of 24-h energy expenditure measurements in humans by indirect calorimetry. Am J Clin Nutr 1990;51(2):147-52.

[3] Westerterp KR, Kester AD. Physical activity in confined conditions as an indicator of free-living physical activity. Obes Res 2003;11(7):865-8.

[4] Westerterp KR, Wilson SA, Rolland V. Diet induced thermogenesis measured over $24 \mathrm{~h}$ in a respiration chamber: effect of diet composition. Int J Obes Relat Metab Disord 1999;23(3):287-92.

[5] Goldberg GR, Prentice AM, Davies HL, Murgatroyd PR. Overnight and basal metabolic rates in men and women. Eur J Clin Nutr 1988;42(2):137-44.

[6] Ravussin E, Burnand B, Schutz Y, Jequier E. Twenty-four-hour energy expenditure and resting metabolic rate in obese, moderately obese, and control subjects. Am J Clin Nutr 1982;35(3):566-73.

[7] Westerterp KR, Meijer GA, Schoffelen P, Janssen EM. Body mass, body composition and sleeping metabolic rate before, during and after endurance training. Eur J Appl Physiol Occup Physiol 1994;69(3):203-8.

[8] Astrup A, Thorbek G, Lind J, Isaksson B. Prediction of 24-h energy expenditure and its components from physical characteristics and body composition in normal-weight humans. Am J Clin Nutr 1990;52(5):777-83.

[9] Buemann B, Astrup A, Christensen NJ, Madsen J. Effect of moderate cold exposure on 24-h energy expenditure: similar response in postobese and nonobese women. Am J Physiol 1992;263(6 Pt 1):E1040-5.

[10] Plasqui G, Kester AD, Westerterp KR. Seasonal variation in sleeping metabolic rate, thyroid activity, and leptin. Am J Physiol 2003;285(2): E338-43.

[11] De Boer JO, Van Es AJ, Vogt JE, Van Raaij JM, Hautvast JG. Reproducibility of $24 \mathrm{~h}$ energy expenditure measurements using a human whole body indirect calorimeter. Br J Nutr 1987;57(2):201-9.

[12] Fontvieille AM, Rising R, Spraul M, Larson DE, Ravussin E. Relationship between sleep stages and metabolic rate in humans. Am J Physiol 1994;267(5 Pt 1):E732-7.

[13] Garby L, Kurzer MS, Lammert O, Nielsen E. Energy expenditure during sleep in men and women: evaporative and sensible heat losses. Hum Nutr 1987;41(3):225-33.

[14] Meijer GA, Westerterp KR, Saris WH, ten Hoor F. Sleeping metabolic rate in relation to body composition and the menstrual cycle. Am J Clin Nutr 1992;55(3):637-40.
[15] Murgatroyd PR, Davies HL, Prentice AM. Intra-individual variability and measurement noise in estimates of energy expenditure by whole body indirect calorimetry. Br J Nutr 1987;58(3):347-56.

[16] Ravussin E, Lillioja S, Anderson TE, Christin L, Bogardus C. Determinants of 24-hour energy expenditure in man. Methods and results using a respiratory chamber. J Clin Invest 1986;78(6):1568-78.

[17] Schoffelen PF, Westerterp KR, Saris WH, Ten Hoor F. A dual-respiration chamber system with automated calibration. J Appl Physiol 1997;83(6): 2064-72.

[18] Westerterp KR. Diet induced thermogenesis. Nutr Metab 2004;1(1):5 [electronic resource].

[19] Wouters-Adriaens MP, Westerterp KR. Basal metabolic rate as a proxy for overnight energy expenditure: the effect of age. Br J Nutr 2006;95(6): $1166-70$.

[20] Zhang K, Sun M, Werner P, Kovera AJ, Albu J, Pi-Sunyer FX, et al. Sleeping metabolic rate in relation to body mass index and body composition. Int J Obes Relat Metab Disord 2002;26(3):376-83.

[21] Webb P, Hiestand M. Sleep metabolism and age. J Appl Physiol 1975;38(2): 257-62.

[22] Fraser G, Trinder J, Colrain IM, Montgomery I. Effect of sleep and circadian cycle on sleep period energy expenditure. J Appl Physiol 1989;66(2):830-6.

[23] Henry CJ, Lightowler HJ, Marchini J. Intra-individual variation in resting metabolic rate during the menstrual cycle. Br J Nutr 2003;89(6):811-7.

[24] Mortola JP. Breathing around the clock: an overview of the circadian pattern of respiration. Eur J Appl Physiol Occup Physiol 2004;91(2-3):119-29.

[25] Webb P. 24-hour energy expenditure and the menstrual cycle. Am J Clin Nutr 1986;44(5):614-9.

[26] Westerterp-Plantenga MS, van Marken Lichtenbelt WD, Strobbe H, Schrauwen P. Energy metabolism in humans at a lowered ambient temperature. Eur J Clin Nutr 2002;56(4):288-96.

[27] van Dale D, Schoffelen PF, ten Hoor F, Saris WH. Effects of addition of exercise to energy restriction on 24-hour energy expenditure, sleeping metabolic rate and daily physical activity. Eur J Clin Nutr 1989;43(7):441-51.

[28] White DP, Weil JV, Zwillich CW. Metabolic rate and breathing during sleep. J Appl Physiol 1985;59(2):384-91.

[29] Weir JBV de. New methods for calculating metabolic rate with special reference to protein metabolism. J Appl Physiol 1949;109(1-2):1-9.

[30] Westerterp KR, Donkers JH, Fredrix EW, Boekhoudt P. Energy intake, physical activity and body weight: a simulation model. Br J Nutr 1995;73(3):337-47.

[31] Webb P. The physiology of heat regulation. Am J Physiol 1995;268(4 Pt 2): R838-50. 